Wärme- und Stoffübertragung 7 (1974) $\quad 31-44$

(c) by Springer Verlag 1974

\title{
Algebraic Methods for the Calculation of Radiation Exchange in an Enclosure
}

\author{
JOHN A. CLARK and MICHAEL E. KORYBALSKI, Ann Arbor, Michigan, USA
}

\begin{abstract}
The algebraic methods of Hottel and Sarofim, Gebhart and one recently published by the authors for the calculation of radiant interchange in an enclosure are examined. Each of these formulations, while written in a different form, is shown to be mathematically equivalent to the others. This equivalence is established by deriving the formulations of Hottel and Sarofim and Gebhart from that of the authors. Because of the analytical complexity of these forms their mathematical equivalence cannot be demonstrated by explicit methods. For this reason proof of equivalence is established by numerical programming using a digital computer. Three different numerical examples are used for this purpose.-In addition, the mathematical structure underlying the absorption factor $B_{i j}$ of Gebhart and the total exchange factor $\overline{S_{i} S_{j}}$ and total view factor $\mathscr{F}_{\mathrm{ij}}$ of Hottel and Sarofim is developed.
\end{abstract}

Zusammenfassung. Die algebraischen Methoden zur Berechnung des Strahlungsaustausches in Hohlräumen von Hottel und Sarofim, Gebhart und von den Autoren dieser Arbeit werden untersucht. Trotz verschiedener Schreibweisen sind die einzelnen Formulierungen mathematisch gleichwertig. Das zeigt sich, wenn man die Formulierungen von Hottel und Sarofim sowie von Gebhart aus der unsrigen ableitet. Wegen der komplizierten mathematischen Form kann diese Äquivalenz nicht explizit gezeigt werden. Sie wurde daher numerisch mit Hilfe eines Digitalrechners an drei Beispielen nachgewiesen. Außerdem wurde die mathematische Struktur des Absorptionsfaktors $B_{i j}$ nach Gebhart, des totalen Austauschfaktors $\overline{S_{\mathbf{i}} S_{\mathbf{j}}}$ und des totalen Flächenverhältnisses $\mathscr{F}_{\mathbf{i j}}$ nach Hottel und Sarofim abgeleitet.

\section{Nomenclature}

\begin{tabular}{|c|c|c|c|}
\hline $\begin{array}{l}A \\
A_{i j}\end{array}$ & $\begin{array}{l}\text { area, }\left[\mathrm{ft}^{2}\right] \\
\text { cofactor of matrix }\left[\mathrm{a}_{\mathbf{i j}}\right], \text { Eq. }(15),[1]\end{array}$ & $q_{j}^{*}$ & $\begin{array}{l}\text { net radiation heat transfer at surface } A_{\mathbf{j}} \text {, } \\
{[\mathrm{Btu} / \mathrm{hr}]}\end{array}$ \\
\hline$\left[a_{i j}\right]$ & $\begin{array}{l}\text { geometric view factor-reflectance matrix, } \\
\text { Eq. (8) }\end{array}$ & RADTQO & $\begin{array}{l}\text { name of authors' computer program to use } \\
\text { with formulation in [12] }\end{array}$ \\
\hline $\begin{array}{l}B_{i j} \\
D\end{array}$ & $\begin{array}{l}\text { Gebhart absorption factor, Eq. (1), [1] } \\
\text { determinant of }\left[a_{i j}\right] \text { matrix, }[1]\end{array}$ & $\mathrm{T}$ & temperature, $\left[{ }^{\circ} \mathrm{R}\right]$ \\
\hline DERGEBHOT & $\begin{array}{l}\text { name of authors' computer program to calcu- } \\
\text { late Gebhart's } B_{i j} \text { and Hottel's } \overline{S_{i} S_{j}}=A \mathscr{A}_{1 j}\end{array}$ & Greek & coordinate \\
\hline$F_{i j}$ & geometric view factor, $[1]$ & $a$ & absorptance or absorptivity, [1] \\
\hline$\left[\mathrm{F}_{\mathrm{ij}}\right]$ & geometric view factor matrix, Eq. (9), [1] & $\beta$ & angle, $[1]$ \\
\hline $\mathscr{F}_{\mathrm{ij}}$ & $\begin{array}{l}\text { Hottel's script-F or total view factor, } \\
\text { Eq. (32), [1] }\end{array}$ & $\begin{array}{l}{\left[\beta_{\mathbf{i j}}\right]} \\
\gamma_{\mathbf{i j}}\end{array}$ & $\begin{array}{l}\text { matrix, Eq. }(25),[1] \\
\text { coefficients of the inverted matrix }\left[a_{i j}\right]^{-1} \text {, }\end{array}$ \\
\hline $\mathbf{H}$ & incident radiation flux, Eq. (3), $\left[\mathrm{Btu} / \mathrm{hr}-\mathrm{ft}^{2}\right]$ & & Eq. (15), [1] \\
\hline$[\mathrm{I}]$ & identity matrix, Eq. (10), [1] & $\begin{array}{l}\epsilon \\
\rho\end{array}$ & $\begin{array}{l}\text { emittance or emissivity, [1] } \\
\text { reflectance or reflectivity, [1] }\end{array}$ \\
\hline $\mathrm{J}$ & $\begin{array}{l}\text { radiosity flux, Eqs. (14), (16), (17), } \\
{\left[\text { Btu/hr-ft }{ }^{2}\right]}\end{array}$ & $\sigma$ & Stefan-Boltzmann constant \\
\hline $\mathrm{K}$ & $\begin{array}{l}(\epsilon / \rho) \sigma \mathrm{T}^{4}, \mathrm{Eq} \cdot(13),\left[\mathrm{Btu} / \mathrm{hr}-\mathrm{ft}^{2}\right] \\
\text { number of surfaces in enclosure, }[1]\end{array}$ & Subscripts & \\
\hline$q_{i j}^{*}$ & $\begin{array}{l}\text { net radiation heat transfer rate between sur- } \\
\left.\text { faces } A_{i} \text { and } A_{j}, E q . \text { ( } 31\right)[B t u / h r]\end{array}$ & $\mathrm{i}$ & $\begin{array}{l}\text { designation of row number in matrix; also ith } \\
\text { surface }\end{array}$ \\
\hline$q_{i j}$ & $\begin{array}{l}\text { energy absorbed at surface } A_{j} \text { originating as } \\
\text { emission at surface } A_{i},[B t u / h r]\end{array}$ & $\mathrm{j}$ & $\begin{array}{l}\text { designation of column number in matrix; also } \\
\text { jth surface }\end{array}$ \\
\hline
\end{tabular}

\section{Introduction}

The exchange of thermal radiation between the surfaces of an enclosure having arbitrary geometry is an important engineering design problem of current interest. Frequently, the information desired in such calculations is either the temperature of the radiating surfaces for a prescribed heat flux rate or the net rate of heat transfer at the surface for specified surface tem-

peratures. In some instances, an enclosure may have heat flux rates fixed for some of the surfaces and temperatures given on others. The calculation of each of these quantities can, furthermore, be determined by the manner in which the enclosure interacts thermally with its external environment. This interaction can take many forms, including both convective and 
radiative exchange with an environment, a fixed external heat flux, an enthalpy transfer by the agency of fluid flow in ducts within the surface or heat generation in the surface. In terms of enclosure analysis these interactive effects represent boundary conditions or constraints imposed on the system of equations governing the radiation exchange within the enclosure. There are also other constraints imposed by the laws of thermodynamics which while not usually explicitly stated, represent immutable limits on both the physical system and the set of equations chosen to describe the system. For a steady-state condition the first law requires the sum of the net internal radiant heat transfer rates at the surfaces to be zero; the second law requires the specification of at least one temperature in the system, either at a surface or in the environment with which the system interacts.

For many engineering design situations the assumption of gray, diffuse radiating surfaces without the presence of participating media is satisfactory. The design calculations in such systems are generally carried out using an algebraic or numerical formulation with subsequent reduction of the equations on a digital computer or, in simple systems, by hand calculations. These kinds of formulations which assume uniform radiosity flux and uniform properties for each surface are numerical approximations to the more exact analytical formulations involving the solution of a system of integral equations. However, the difficulties encountered in the solution of such equations for an enclosure of arbitrary geometry are so enormous as to render any general attempt impractical for design purposes. On the other hand, the various algebraic methods may be relatively easily applied to very complex systems providing results having excellent correspondence with the more exact formulations. This is particularly true when a large memory digital computer is available for programming and solving the governing system of equations. Furthermore, the condition of variable surface radiosity flux, temperature and surface properties can be approximated to almost any degree by subdividing a surface into sufficiently small sub-sections. The penalty for this improvement is an increase in the magnitude and cost of the calculations.

In recent years several algebraic methods for radiation enclosure analysis and calculation have been published. Probably the earliest of these is that of Hottel [1]. Later this work was expanded by Hottel and Sarofim [2]. The basis for their method is the concept of the radiosity heat flux and, hence, is sometimes referred to as a radiosity method. Gebhart [3, 4] has approached the problem of enclosure analysis in a different way. His method is based on the definition of an absorption factor, the fraction of energy absorbed at a surface which originates as emission at another surface. Other work dealing with radiant exchange between the surfaces of an enclosure include those of Sparrow [5], Sparrow and Cess [6], Oppenheim [7], Eckert and Drake [8], Love [9], Wiebelt [10] and Siegel and Howell [11].

Recently the authors have published a paper on this problem [12] which treats an enclosure having gray, diffuse surfaces that are adiabatic or of known temperature. The formulation of this method is based on the concept of radiosity heat flux and is similar to that of Hottel [1, 2] although formulated in somewhat different manner. The emphasis is on engineering design application with the governing equations written for convenience in computer programing. The analysis is coupled with the external thermal interactions of the enclosure with its environment. A number of examples of the use of the method to enclosures are given and a comparison is made with the results of Hottel $[1,2]$ and Hottel and Sarofim [2] and Gebhart [3].

The various algebraic methods for enclosure analysis are mathematically identical. Although formulated in different ways their differences represent only the varying mathematical and physical perspectives of their authors. For a given set of conditions, each method produces results identical to that of the others. Usually certain types of calculations are more conveniently made with one method, rather than another, owing to the manner of its formulation. It is also possible to derive the form of any of the methods using another as a starting point.

The purpose of the present paper is to demonstrate the equivalence of the algebraic methods of Hottel and Sarofim [1,2], Gebhart [3] and that given by the authors [12]. The equivalence will be established by using the enclosure analysis in [12] to derive the methods of [1,2 and 3]. Specific numerical examples will then be given in which numerical results using each method are compared. These results will also be compared with such independent calculations made by others as are available. All numerical calculations made by the present authors were performed using the IBM 360/67 Digital Computer of The University of Michigan Computing Center.

In addition to showing equivalence of the various methods for enclosure calculations, a fundamental derivation of the elements which form the Gebhart absorption factor, $B_{i j}$, the Hottel total-view factor, $\mathscr{F}_{\mathrm{ij}}$, and the total-exchange area, $\overline{\mathrm{S}_{\mathrm{i}} \mathrm{S}_{\mathrm{j}}}$, of Hottel and Sarofim will be given. All computer calculations have been performed using the author's program named DERGEBHOT.

\section{Derivation of Gebhart's Absorption Factors}

An enclosure of $n$-surfaces having arbitrary geometry is shown in Fig. 1. It will be assumed that all surfaces have gray, diffuse radiation characteristics. The consequences and applicability of this assumption are well documented $[2,6,12]$. Further, the temperature and 


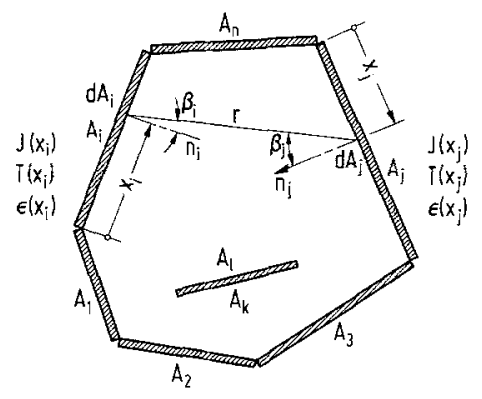

Fig. 1. A general n-surface enclosure encompassing $4 \pi$-steradians solid angle

radiosity flux are assumed to be uniform over each surface. As a practical matter these assumptions are usually necessary for engineering design calculations and do represent approximations that closely resemble those circumstances often found in practice. The enclosure is filled with a non-participating medium.

Gebhart's absorption factor [3], $B_{\mathbf{i j}}$, is defined as the fraction of radiation emitted by surface $A_{i}$ that is absorbed by surface $A_{j}$ considering all paths of radiant exchange between $A_{i}$ and $A_{j}$. Hence,

$$
\begin{aligned}
\mathrm{B}_{\mathbf{i j}} & =\frac{\text { Energy Absorbed at } \mathrm{A}_{\mathbf{j}} \text { originating as emission at } \mathrm{A}_{\mathbf{i}}}{\epsilon_{\mathrm{i}} \mathrm{A}_{\mathbf{i}} \sigma \mathrm{T}_{\mathbf{i}}^{4}} \\
& =\frac{\mathrm{q}_{\mathrm{ij}}}{\epsilon_{\mathbf{i}} \mathrm{A}_{\mathbf{i}} \sigma \mathrm{T}_{\mathrm{i}}^{4}}
\end{aligned}
$$

The heat transfer rate incident on surface $A_{j}$ may be written [12] in terms of the incident flux, $\mathrm{H}_{\mathrm{j}}$, the radiosity fluxes of all $n$ surfaces, $J_{1}, \ldots J_{n}$, and the geometric view factors $F_{1 j}, \ldots, F_{n j}$, considering emission and reflection from all n-surfaces, as

$A_{j} H_{j}=F_{1 j} A_{1} J_{1}+F_{2 j} A_{2} J_{2}+\ldots+F_{n j} A_{n} J_{n}$

Since by the reciprocal (geometric) relations $F_{1 j} A_{1}=$ $=F_{j 1} A_{j}, F_{2 j} A_{2}=F_{j 2} A_{j}$, etc., the incident flux on $A_{j}$ becomes

$$
\begin{gathered}
H_{j}=F_{j 1} J_{1}+F_{j 2} J_{2}+\ldots+F_{j n} J_{n} . \\
(j=1,2 \ldots n)
\end{gathered}
$$

Now, the energy absorbed at $A_{j}$ for emission and reflection from all $n$-surfaces may be written as

$q_{i j}=\alpha_{j} A_{j} H_{j} . \quad(j=1,2 \ldots n)$

To relate these results to the absorption factor, $B_{i j}$, of Eq. (1), it is necessary to identify the energy absorbed at $A_{\mathbf{j}}$, that is $q_{\mathbf{i j}}$, with that energy which originated only at surface $A_{i}$ as emission. As written in Eq. (4) $q_{j}$ is the energy absorbed at $A_{j}$ resulting from simultaneous emission and reflection of energy from all the $n$-surfaces in the enclosure. Owing to the complexity of radiant interchange, as expressed in Eq. (4), it is difficult to isolate that fraction of $q_{j}$ that originated as emission from $A_{i}$. However, it is possible to determine that portion of $q_{j}$ which originated as emission from $A_{i}$ if a change is made in the analytical model, Fig. 1. This is to set the temperatures of all $n$-surfaces to zero, except $A_{i}$, which has a finite temperature $T_{i}$. In this instance, then, it is only $A_{i}$ which is a source of energy since all other surfaces, including $A_{\mathfrak{j}}$, being at zero temperature, emit no energy but can only absorb and reflect. Hence, an energy absorbed at any surface, including $A_{j}$, under these circumstances originates as emission from $A_{i}$ as a source. Accordingly, $\mathrm{H}_{\mathrm{j}}$ can be computed directly from Eq. (3) in terms of the radiosity fluxes, $J_{1}, \ldots, J_{n}$, existing at all the surfaces under the conditions of a finite temperature only at $A_{i} \cdot 1$ While this model is hypothetical, the resulting $B_{i j}$ have genuine physical significance.

Thus, the energy absorbed at $A_{j}$ originating as emission from $A_{i}$, including all paths for interchange becomes from Eq. (4)

$$
\begin{aligned}
q_{i j}= & \alpha_{\mathbf{j}} A_{\mathbf{j}} H_{\mathbf{i j}}, \\
& (i=1,2 \ldots n) \quad(j=1,2 \ldots n)
\end{aligned}
$$

where, $H_{\mathbf{i j}}$ is the partial incident energy flux on $\mathbf{A}_{\mathbf{j}}$ originating as emission at $A_{i}$ and is found using Eq. (3). The radiosity fluxes in Eq. (3) are those existing under the circumstances of zero temperatures on all surfaces except $A_{i}$ and may be considered as partial radiosity fluxes. To keep the notation as simple as possible, however, these fluxes will be designated with a single subscript only. Thus,

$$
\begin{gathered}
q_{i j}=\alpha_{j} A_{j}\left(F_{j 1} J_{1}+F_{j 2} J_{2}+\ldots+F_{j n} J_{n}\right) \\
(i=1,2 \ldots n)(j=1,2 \ldots n)
\end{gathered}
$$

The various radiosity fluxes $J_{1}, J_{2}, \ldots, J_{n}$, are determined by the formulation given in [12], as

$$
\begin{aligned}
& {\left[\mathrm{a}_{\mathbf{i j}}\right]\left[\mathrm{J}_{\mathbf{j}}\right] }+\left[\mathrm{K}_{\mathbf{i}}\right]=0, \\
&(\mathrm{i}=1,2 \ldots \mathrm{n}) \quad(\mathrm{j}=1,2 \ldots \mathrm{n})
\end{aligned}
$$

where, the following matrixes are defined [12]

$$
\left[\mathrm{a}_{\mathrm{ij}}\right]=\left[\mathrm{F}_{\mathrm{ij}}\right]-\frac{1}{\rho_{\mathrm{i}}}[\mathrm{I}]
$$

\footnotetext{
${ }^{1}$ Under these circumstances the fraction of energy absorbed at $A_{j}$, originating as emission only at $A_{i}$, is designated as $q_{i j}$, a partial absorbed energy at $\mathbf{A}_{\mathbf{j}}$. Also, the corresponding partial incident energy flux at $\mathbf{A}_{\mathbf{j}}$ is written as $\mathrm{H}_{\mathbf{i j}}$.
} 
and,

$$
\begin{aligned}
{\left[F_{i j}\right] } & =\left[\begin{array}{cccc}
F_{11} & F_{12} & \ldots & F_{1 n} \\
F_{21} & F_{22} & \ldots & F_{2 n} \\
\cdot & \cdot & & \vdots \\
\cdot & \cdot & & \cdot \\
F_{n 1} & F_{n 2} & \ldots & F_{n n}
\end{array}\right] \\
{[I] } & =\left[\begin{array}{cccc}
1 & 0 & \ldots & 0 \\
0 & 1 & \ldots & 0 \\
\cdot & \cdot & & \cdot \\
\cdot & \cdot & & \cdot \\
0 & 0 & \ldots & 1
\end{array}\right]
\end{aligned}
$$$$
\left[\mathrm{J}_{\mathrm{j}}\right]=\left[\begin{array}{c}
\mathrm{J}_{1} \\
\mathrm{~J}_{2} \\
\cdot \\
\vdots \\
\mathrm{J}_{\mathrm{n}}
\end{array}\right] \quad(11), \quad\left[\mathrm{K}_{\mathrm{i}}\right]=\left[\begin{array}{c}
\mathrm{K}_{1} \\
\mathrm{~K}_{2} \\
\cdot \\
\cdot \\
\mathrm{K}_{\mathrm{n}}
\end{array}\right]
$$

where

$$
\mathrm{K}_{\mathrm{i}}=\left(\frac{\epsilon}{\rho}\right)_{\mathbf{i}} \sigma \mathrm{T}_{\mathrm{i}}^{4} . \quad(\mathrm{i}=1,2 \ldots \mathrm{n})
$$

As will be noted the matrix $\left[F_{\mathbf{i j}}\right]$ is the geometric view factor matrix, [I] is an identity matrix and both $\left[\mathrm{J}_{\mathrm{j}}\right]$ and $\left[\mathrm{K}_{\mathrm{i}}\right]$ are column matrixes. Information required to establish numerical values for each of these matrixes are those physical and geometric data normally available in an engineering problem. For the developments in [12] it was assumed that surface temperatures are specified, the conditions required in this present analysis.

The solution of Eq. (7) for the $J_{j}$ radiosity fluxes is found from elementary matrix algebra to be [12]

$$
\begin{aligned}
{\left[\mathrm{J}_{\mathbf{j}}\right]=} & -\left[\mathrm{a}_{\mathbf{i j}}\right]^{-1}\left[\mathrm{~K}_{\mathbf{i}}\right], \\
& (\mathrm{i}=1,2 \ldots \mathrm{n})(\mathrm{j}=1,2 \ldots \mathrm{n})
\end{aligned}
$$

where $\left[a_{i j}\right]^{-1}$ is the inverse of matrix $\left[a_{i j}\right]$ and may be written

$\left[\mathrm{a}_{\mathrm{ij}}\right]^{-1}=\frac{1}{\mathrm{D}}\left[\mathrm{A}_{\mathrm{ji}}\right]=\left[\gamma_{\mathrm{ij}}\right]$

in which $D$ is the determinant of $\left[a_{i j}\right]$ and $\left[A_{j i}\right]$ is the transposed matrix of cofactors $\left[\mathrm{A}_{\mathrm{ij}}\right]$ of $\left[\mathrm{a}_{\mathrm{ij}}\right] \cdot \gamma_{\mathrm{ij}}$ are the elements of the inverted matrix $\left[a_{i j}\right]^{-1}$. Thus, the radiosity fluxes are written as

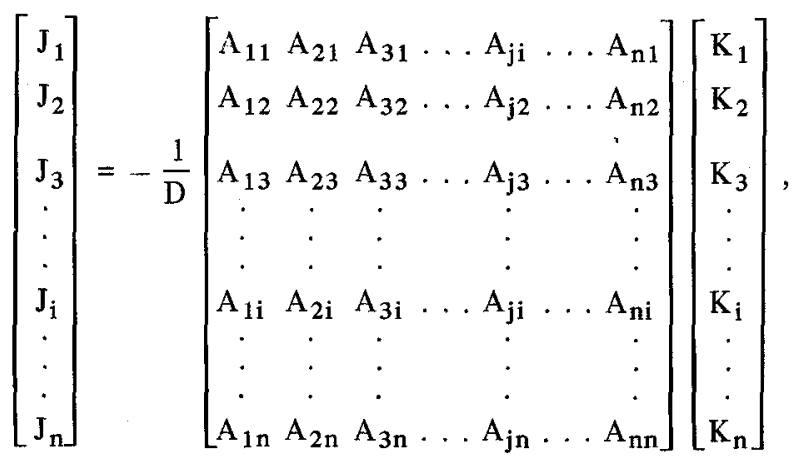

with $\mathrm{K}_{\mathbf{i}}$ given by $\mathrm{Eq}$. (13). In the actual numerical calculations with a digital computer, the elements $\gamma_{i j}$ to the inverted matrix $\left[a_{i j}\right]^{-1}$ are determined rather than the determinant $D$ and the cofactors $A_{j i}$. However, for purposes of analysis the algebraic representation using cofactors has the advantage of showing the mathematical structure of the result.

Now, with all surface temperatures equal to zero, except $T_{\mathbf{i}}$, the column matrix $\left[\mathbf{K}_{\mathbf{i}}\right]$ in Eq. (16) becomes

$$
\left[\begin{array}{c}
0 \\
0 \\
: \\
\mathbf{K}_{\mathbf{i}} \\
: \\
0
\end{array}\right]
$$

Hence, the corresponding radiosity fluxes for zero temperatures on all surfaces except $A_{\mathbf{i}}$ become,

$$
\begin{gathered}
J_{1}=-\frac{A_{j 1}}{D} K_{i}=-\frac{A_{i 1}}{D} K_{i} \\
J_{2}=-\frac{A_{j 2}}{D} K_{i}=-\frac{A_{i 2}}{D} K_{i} \\
\vdots \\
\vdots \\
J_{n}=-\frac{A_{j n}}{D} K_{i}=-\frac{A_{i n}}{D} K_{i}
\end{gathered}
$$

since all products of coefficients in the matrix product $\left[A_{j i}\right]\left[K_{i}\right]$ will be zero except those in the column associated with $\mathbf{j}=i$ in the $\left[\mathrm{A}_{\mathrm{ji}}\right]$ matrix. 
The absorption factor $B_{\mathrm{ij}}$ is now formulated from Eq. (1), using the results in Eqs. (6) and (17), as

$$
\begin{aligned}
\mathrm{B}_{\mathrm{ij}}=- & \frac{\alpha_{\mathrm{j}}\left(\mathrm{A}_{\mathrm{j}} / \mathrm{A}_{\mathrm{i}}\right)}{\mathrm{D} \epsilon_{\mathrm{i}} \sigma \mathrm{T}_{\mathrm{i}}^{4}}\left(\frac{\epsilon}{\rho}\right)_{\mathrm{i}} \sigma \mathrm{T}_{\mathrm{i}}^{4} \times \\
& \times\left(\mathrm{F}_{\mathrm{j} 1} \mathrm{~A}_{\mathrm{i} 1}+\mathrm{F}_{\mathrm{j} 2} \mathrm{~A}_{\mathrm{i} 2}+\ldots+\mathrm{F}_{\mathrm{jn}} \mathrm{A}_{\mathrm{in}}\right),
\end{aligned}
$$

or, by introducing the grayness assumption $\alpha_{j}=\epsilon_{\mathrm{j}}$ and $\rho_{\mathbf{i}}=1-\epsilon_{\mathbf{i}}$ and eliminating the temperature $\mathrm{T}_{\mathbf{i}}$, the absorption factor $\mathbf{B}_{\mathbf{i j}}$ becomes
Furthermore, from the summation in Eq. (21) it may be recognized that the column it represents in the $\left[\beta_{\mathrm{ij}}\right]-$ matrix permits the entire matrix to be written

$\left[\beta_{i j}\right]=-\frac{1}{D}\left[\left[F_{i j}\right]\left[A_{j i}\right]\right]^{T}$

where, $[\quad]^{\mathrm{T}}$ signifies the transpose of the matrix product. By the rules of matrix algebra, the transpose of the product of two matrixes is the product in reverse order of their transposed matrixes. Hence,

$B_{i j}=-\frac{\epsilon_{j}\left(A_{j} / A_{i}\right)}{D\left(1-\epsilon_{i}\right)}\left(F_{j 1} A_{i 1}+F_{j 2} A_{i 2}+\ldots+F_{j n} A_{i n}\right), \quad\left[\beta_{i j}\right]=-\frac{1}{D}\left[A_{i j}\right]\left[F_{j i}\right]$

or,

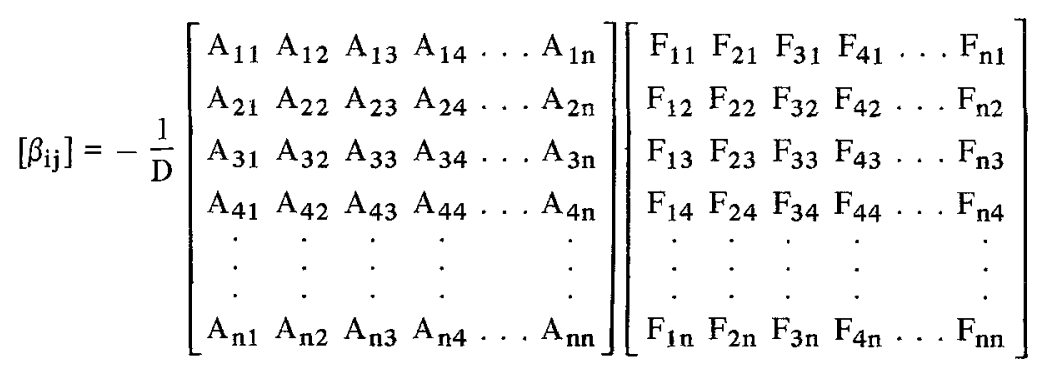

in which $i, j=1,2 \ldots$ n. Eq. (19) may also be written

$$
\begin{aligned}
B_{i j}=- & \frac{\epsilon_{j}\left(A_{j} / A_{i}\right)}{D\left(1-\epsilon_{i}\right)} \sum_{k=1}^{n} F_{j k} A_{i k}, \\
& (i=1,2 \ldots n), \quad(j=1,2 \ldots n)
\end{aligned}
$$

or, as

$$
\begin{gathered}
\left(\frac{A_{i}}{A_{j}}\right)\left(\frac{1-\epsilon_{i}}{\epsilon_{j}}\right) B_{i j}=-\frac{1}{D} \sum_{k=1}^{n} F_{j k} A_{i k} . \\
(i=1,2 \ldots n), \quad(j=1,2 \ldots n)
\end{gathered}
$$

If the quantity $\beta_{\mathrm{ij}}$ is defined as

$$
\begin{aligned}
\beta_{i j}= & \left(\frac{A_{i}}{A_{j}}\right)\left(\frac{1-\epsilon_{i}}{\epsilon_{j}}\right) B_{i j}, \\
& (i=1,2 \ldots n), \quad(j=1,2 \ldots n)
\end{aligned}
$$

it will be noted that each $\beta_{\mathrm{ij}}$, in Eq. (22) is an element in an $n^{2}$-matrix, which may be designated as the $\left[\beta_{i j}\right]-$ matrix. Thus,

$\left[\beta_{i j}\right]=\left[\frac{A_{i}}{A_{j}}\left(\frac{1-\epsilon_{i}}{\epsilon_{j}}\right) B_{i j}\right]$

$$
(i=1,2 \ldots n),(j=1,2 \ldots n)
$$

Wärme- und Stoffübertragung 7 (1974) No. 1
In this result the first matrix is the matrix of cofactors [Aij] for the matrix $\left[a_{i j}\right]$ and the second matrix is the transpose of the view factor matrix $\left[F_{i j}\right]$. It might be stated again that during machine computation of the $\left[\beta_{\mathrm{ij}}\right]$-matrix in Eq. (26) the elements $\gamma_{\mathrm{ij}}$ of the inverse $\left[a_{i j}\right]$ matrix are used instead of the elements $A_{i j} / D$.

This is done as a matter of computational convenience. For a given column index $\mathrm{j} \mathrm{Eq.} \mathrm{(26)} \mathrm{gives} \mathrm{an} \mathrm{identical}$ result as that found from Eq. (21).

Hence, the absorption factor $B_{i j}$ introduced by Gebhart [3] may be written as

$$
\left[\frac{A_{i}}{A_{j}}\left(\frac{1-\epsilon_{i}}{\epsilon_{j}}\right) B_{i j}\right]=-\frac{1}{D}\left[A_{i j}\right]\left[F_{j i}\right]=\left[\beta_{i j}\right]
$$

$$
(i=1,2 \ldots n)(j=1,2 \ldots n)
$$

The absorption factor $\mathrm{B}_{34}$ would be determined, for example, for $i=3, j=4$, from

$$
\begin{aligned}
\beta_{34}= & \frac{A_{3}}{A_{4}}\left(\frac{1-\epsilon_{3}}{\epsilon_{4}}\right) B_{34}= \\
= & -\frac{1}{D}\left(A_{31} F_{41}+A_{32} F_{42}+\right. \\
& \left.+A_{33} F_{43}+\ldots+A_{3 n} F_{4 n}\right)
\end{aligned}
$$

And a typical absorption factor for a surface radiating 
to itself is written, for example, for $i=3, j=3$, as

$$
\begin{aligned}
\beta_{33}= & \left(\frac{1-\epsilon_{3}}{\epsilon_{3}}\right) B_{33}= \\
= & \frac{1}{D}\left(A_{31} F_{31}+A_{32} F_{32}+\right. \\
& \left.+A_{33} F_{33}+\ldots+A_{3 n} F_{3 n}\right)
\end{aligned}
$$

This last result shows that while a surface may not radiate directly to itself (i. e., for $\mathrm{F}_{\mathbf{3 3}}=0$ ) it will radiate to itself indirectly by reflection from the other $\mathrm{n}-1$ surfaces in the enclosure. Further, the mathematical description of the mechanics of this physical event is given by Eq. (29).

The matrixes in Eq. (27) indicate those variables by which the absorption factor is determined. The right hand side of Eq. (27) involves only those quantities found in the $\left(a_{i j}\right)$ matrix, Eq. (8), namely, the geometric view factors, $F_{i j}$, and the reflectances $\rho_{\mathbf{i}}$ of each surface. The terms multiplying $B_{i j}$ in $\beta_{i j}$ are the surfaces areas $A_{i}$ and $A_{j}$ and the reflectance $\rho_{i}$ and emittance $\epsilon_{\mathbf{j}}$. Thus, from the geometric and physical data used to define the properties of an enclosure the elements $B_{\mathbf{i j}}$ of the entire $B_{i j}$-matrix can be calculated using Eq. (27). This will be done later in this paper for three examples. It is interesting to note that surface temperatures do not influence the calculation of each $B_{\mathbf{i j}}$. The independence of the absorption factors from the surface temperatures is an important characteristic of Gebhart's method, something easily demonstrated by Eq. (27). However, the energy $q_{i j}$, absorbed at $A_{j}$ originating as emission at $A_{i}$ is directly related to the temperature at $A_{i}$, by Eq. (1). Thus, it is possible to have finite values of the absorption factor $B_{i j}$ but $a$ zero value for $q_{i j}$ for those cases of $T_{i}$ equal to zero. An example of this circumstance will be cited later. In general, all absorption factors $B_{\mathbf{i j}}$ will be finite for all real, gray systems of a given geometry, as indicated by Eqs. (23)-(29), because these factors are properties of an enclosure and related to the geometric configuration and radiation properties of the surfaces. The rates of heat transfer by absorption and emission, however, are determined, in addition to the $B_{i j}$, by the surface temperatures. Thus, the absorption factors themselves cannot be used as an indicator of the absolute rates of energy transfer in an enclosure without also including the effect of the surface temperatures.

The net heat transfer rate at $A_{j}$ resulting from the exchange of radiation with all $n$-surfaces in the enclosure each having a specified temperature may be written (3) as

$$
\begin{gathered}
q_{j}^{*}=\epsilon_{j} A_{j} \sigma T_{j}^{4}-\sum_{i=1}^{n} \epsilon_{i} A_{i} B_{i j} \sigma T_{i}^{4} . \\
(j=1,2 \ldots n)
\end{gathered}
$$

In the examples that follow the net heat transfer rate at each surface of an enclosure will be computed using Eq. (30), from Gebhart [3], but with the absorption factors determined using the derivation given in this paper, Eq. (27). The temperatures of each surface may be specified arbitrarily in using Eq. (30) and may include some with zero temperature.

\section{Derivation of The Hottel and Sarofim Factors $\overline{S_{i} S_{j}}$ and $\overline{\mathscr{F}_{1 j}}$}

Hottel and Hottel and Sarofim [1, 2] define the two factors $\overline{S_{i} S_{j}}$ and $\mathscr{F}_{\mathbf{j} j}$ as the total-exchange area and the total view factor, respectively. Their role in radiant interchange is related to the calculation of the net rate of heat transfer $q_{i j}^{*}$ between $A_{i}$ and $A_{j}$. For the enclosure in Fig. 1 for all surfaces at zero temperature except $\mathrm{T}_{\mathbf{i}}$ and $\mathrm{T}_{\mathrm{j}}, \mathrm{q}_{\mathbf{i j}}^{*}$ is written

$$
\begin{aligned}
\mathrm{q}_{\mathrm{ij}}^{*} & =\overline{\mathrm{S}_{\mathrm{i}} \mathrm{S}_{\mathrm{j}}} \sigma\left(\mathrm{T}_{\mathrm{i}}^{4}-\mathrm{T}_{\mathrm{j}}^{4}\right) \\
& =\mathrm{A}_{\mathbf{i}} \mathscr{F}_{\mathrm{ij}} \sigma\left(\mathrm{T}_{\mathrm{i}}^{4}-\mathrm{T}_{\mathbf{j}}^{4}\right) .
\end{aligned}
$$

The net rate of heat exchange may also be written in terms of Gebhart's absorption factors for these same conditions, as

$\mathrm{q}_{\mathrm{ij}}^{*}=\mathrm{A}_{\mathrm{i}} \epsilon_{\mathrm{i}} \sigma \mathrm{T}_{\mathrm{i}}^{4} \mathrm{~B}_{\mathrm{ij}}-\mathrm{A}_{\mathrm{j}} \epsilon_{\mathrm{j}} \sigma \mathrm{T}_{\mathrm{j}}^{4} \mathrm{~B}_{\mathrm{ji}}$.

However, Gebhart has shown [3] that a reciprocal relationship exist between the quantities in Eq. (33) such that

$A_{i} \epsilon_{i} B_{i j}=A_{j} \epsilon_{j} B_{j i}$

Hence,

$q_{i j}^{*}=\epsilon_{i} A_{i} B_{i j} \sigma\left(T_{i}^{4}-T_{j}^{4}\right)$.

Thus, from the results in Eqs. (31, 32 and 35) the factors $\overline{S_{\mathbf{i}} S_{\mathbf{j}}}$ and $\mathscr{F}_{\mathbf{i} j}$ may be related to the absorption factor $B_{\mathbf{i j}}$ as

$$
\begin{aligned}
\epsilon_{\mathbf{i}} \mathrm{A}_{\mathbf{i}} \mathrm{B}_{\mathbf{i j}} & =\overline{\mathrm{S}_{\mathbf{i}} \mathrm{S}_{\mathbf{j}}} \\
& =\mathrm{A}_{\mathbf{i}} \mathscr{F}_{\mathbf{i j}} .
\end{aligned}
$$

Accordingly, from Eq. (27), the factors $\overline{S_{i} S_{j}}$ and $\mathscr{F}_{i j}$ can be shown to be

$\overline{S_{i} S_{j}}=A_{j} \frac{\epsilon_{i} \epsilon_{j}}{1-\epsilon_{i}} \beta_{i j}$

and 
where $\beta_{\mathrm{ij}}$ is an element in the matrix

$\left[\beta_{\mathbf{i j}}\right]=-\frac{1}{\mathrm{D}}\left[\mathrm{A}_{\mathbf{i j}}\right]\left[\mathrm{F}_{\mathbf{j i}}\right]$

$$
(i=1,2 \ldots n)(j=1,2 \ldots n)
$$

These formulations for $\overline{S_{\mathbf{i}} S_{j}}$ and $\overline{F_{i j}}$ are different in structure from those of Hottel and Sarofim [1,2] but are mathematically equivalent to them.

The development leading to Eqs. (38) and (39) indicates that the factors $\overline{S_{i} S_{j}}$ and $\mathscr{F}_{j j}$ are composed of the same quantities as is the absorption factor $B_{i j}$ and can, in fact, be derived from $B_{i j}$, as

$\overline{S_{i} S_{j}}=\epsilon_{i} A_{i} B_{i j}$

and

$\mathscr{F}_{\mathrm{ij}}=\epsilon_{\mathrm{i}} \mathrm{B}_{\mathrm{ij}}$

While Eqs. (36) and (40) show the relation of $\overline{\mathrm{S}_{\mathrm{i}} \mathrm{S}_{\mathrm{j}}}$ and $\widetilde{F_{i j}}$ to $B_{i j}$, Eqs. (38) and (39) would be used to compute these factors from the corresponding element $\beta_{\mathrm{ij}}$ and the geometric and physical data used to describe an enclosure. Thus, $\mathrm{S}_{3} \mathrm{~S}_{4}$ and $\mathscr{F}_{34}$, for example, are written from Eqs. (28), (38) and (39) as,

$$
\begin{aligned}
\overline{\mathrm{S}_{3} \mathrm{~S}_{4}=} & \mathrm{A}_{4} \frac{\epsilon_{3} \epsilon_{4}}{1-\epsilon_{3}} \beta_{34} \\
= & -\frac{\mathrm{A}_{4}}{\mathrm{D}} \cdot \frac{\epsilon_{3} \epsilon_{4}}{1-\epsilon_{3}} \times \\
& \times\left(\mathrm{A}_{31} \mathrm{~F}_{41}+\mathrm{A}_{32} \mathrm{~F}_{42}+\ldots+\mathrm{A}_{3 \mathrm{n}} \mathrm{F}_{4 \mathrm{n}}\right) \\
= & \mathrm{A}_{3} \mathscr{F}_{34} .
\end{aligned}
$$

The net heat transfer rate $q_{j}^{*}$ at surface $A_{j}$ considering energy exchange with all $n$-surfaces in the enclosure can be expressed in terms of the factors $\overline{\mathrm{S}_{\mathrm{i}} \mathrm{S}_{\mathrm{j}}}$ and $\mathscr{\mathscr { F } _ { \mathrm { ij } }}$ from Eqs. (30), (36) and (37) as

$$
\begin{gathered}
q_{j}^{*}=\epsilon_{j} A_{j} \sigma T_{j}^{4}-\sum_{i=1}^{n} \overline{S_{i} S_{j}} \sigma T_{i}^{4}, \\
(j=1,2 \ldots n)
\end{gathered}
$$

or

$$
\begin{gathered}
q_{j}^{*}=\epsilon_{j} A_{j} \sigma T_{j}^{4}-\sum_{i=1}^{n} \mathscr{F}_{i j} A_{i} \sigma T_{i}^{4}, \\
(j=1,2 \ldots n) .
\end{gathered}
$$

For the numerical examples given later, the $q_{j}^{*}$ for the method of Hottel and Sarofim is determined from Eqs. (42) and (43) using the values of $\overline{S_{i} S_{j}}$ and $\overline{\mathscr{F}_{i j}}$ calculated from the derivations given in this paper, namely, Eqs. (38) and (39).

Some interesting and related consequences may be derived from this evaluation of $\overline{S_{i} S_{j}}$ and $\mathscr{F}$. The factor $\mathscr{F}_{\mathrm{ij}}$ can be written

$$
\begin{aligned}
\mathscr{F}_{\mathbf{i j}} & =\epsilon_{\mathrm{i}} \frac{\mathrm{q}_{\mathrm{ij}}}{\epsilon_{\mathrm{i}} \mathrm{A}_{\mathrm{i}} \sigma \mathrm{T}_{\mathrm{i}}^{4}} \\
& =\frac{\mathrm{q}_{\mathrm{ij}}}{\mathrm{A}_{\mathbf{i}} \sigma \mathrm{T}_{\mathrm{i}}^{4}}
\end{aligned}
$$

or

$\mathscr{F}_{1 j}=\frac{\text { energy absorbed at } A_{j} \text { originating as emission at } A_{i}}{\text { total black radiation from } A_{i} \text { at temperature } T_{i}}$.

Hence, from this result it may be seen that the factor $\mathscr{T}_{i j}$ is really another form of an absorption factor, based on the total black radiation from the originating surface rather than on its gray emission, as is the case with Gebhart's $B_{i j}$. Further, the factor $\overline{S_{i} S_{j}}$ also may be interpreted as an absorption factor since it is simply related to $\mathscr{F}_{\mathrm{ij}}$ by the relation

$$
\begin{aligned}
\overline{S_{i} S_{j}} & =A_{i} \mathscr{F}_{i j} \\
& =\frac{q_{i j}}{\sigma T_{i}^{4}}
\end{aligned}
$$

or

$\overline{S_{i} S_{j}}=\frac{\text { energy absorbed at } A_{j} \text { originating as emission at } A_{i}}{\text { black radiation flux from } A_{i} \text { having temperature } T_{i}}$

From Eq. (37) some additional interpretation concerning the factor $\mathscr{F}_{\mathrm{ij}}$ will be included. This factor is related to $B_{\mathbf{i j}}$ by

$$
\mathscr{F}_{\mathrm{ij}}=\epsilon_{\mathrm{i}} \mathrm{B}_{\mathrm{ij}}
$$

Now, if the summation is formed over the index $j$

$$
\sum_{\mathbf{j}=1}^{\mathbf{n}} \mathscr{F}_{\mathbf{i j}}=\epsilon_{\mathbf{i}} \sum_{\mathbf{j}=1}^{\mathbf{n}} \mathbf{B}_{\mathbf{i j}}, \quad(\mathrm{i}=1,2, \ldots \mathrm{n})
$$

and, since by the physical constraints (3) on the radiation

$$
\sum_{j=1}^{n} B_{i j}=1.0 . \quad(i=1,2, \ldots n)
$$


Hence,

$$
\sum_{\mathrm{j}=1}^{\mathrm{n}} \mathscr{F}_{\mathrm{ij}}=\epsilon_{1}, \quad(\mathrm{i}=1,2, \ldots \mathrm{n})
$$

or

$\mathscr{F}_{11}+\mathscr{F}_{12}+\mathscr{F}_{13}+\ldots+\mathscr{F}_{1 \mathrm{n}}=\epsilon_{1}$

$\mathscr{F}_{21}+\mathscr{F}_{22}+\mathscr{F}_{23}+\ldots+\mathscr{F}_{2 \mathrm{n}}=\epsilon_{2}$

$\mathscr{F}_{\mathrm{n} 1}+\mathscr{F}_{\mathrm{n} 2}+\mathscr{F}_{\mathrm{n} 3}+\ldots+\mathscr{F}_{\mathrm{nn}}=\epsilon_{\mathrm{n}}$

This means that the sum of the $\mathscr{F}_{\mathrm{ij}}$ factors in each row of the $\left(\mathscr{F}_{i j}\right)$-matrix must equal the emittance of the surface having the same index as that row, i. e., $\mathbf{A}_{\mathbf{i}}$. Should the $\left[\mathscr{F}_{\mathbf{i j}}\right]$-matrix be employed in the calculation, the constraints in Eq. (51) can be used as a check in the numerical results. This constraint is completely similar as that in each row of the $\left[F_{i j}\right]$-matrix, that is

$\sum_{j=1}^{n} F_{i j} \equiv 1.0 . \quad(i=1,2, \ldots n)$

In fact, for black systems Eq. (51) is identical to Eq. (53), since not only will $\epsilon_{\mathrm{i}}$ be equal to 1.0 , but the factor $\mathscr{F}_{\mathrm{ij}}$ is identical to $\mathrm{F}_{\mathbf{i j}}$ under these circumstances. Furthermore, for black systems the following relations will always hold

$$
\begin{aligned}
\mathscr{F}_{\mathbf{i j}} & =B_{\mathbf{i j}} \\
& =F_{\mathbf{i j}},
\end{aligned}
$$

and

$\widetilde{S_{1} S_{j}}=A_{i} F_{i j}$

\section{Numerical Results}

Three numerical examples are chosen to compare results using the authors' method with computer program RADTQO [12] and those determined from the methods of Gebhart [3] and Hottel and Sarofim [1,2], as derived in the previous section using Eqs. (27), (30), (38), (39), (42), and (43). The computer program for this later calculation is known as DERGEBHOT. As an additional check the results for the first example will also be compared with an independent calculation prepared by Gebhart [3, 13]. The three examples are shown in Figs. 2, 3, and 4.

The first example, Fig. 2, taken from Gebhart [3], is a 4-surface gray enclosure having 3 specified surface temperatures and 1 adiabatic surface. In Gebhart's original problem surfaces 1 and 3 are black. This condition is approximated here by establishing the emittances of both $\mathrm{A}_{1}$ and $\mathrm{A}_{3}$ as 0.99999 and their corresponding reflectances as 0.00001 . With the decimal

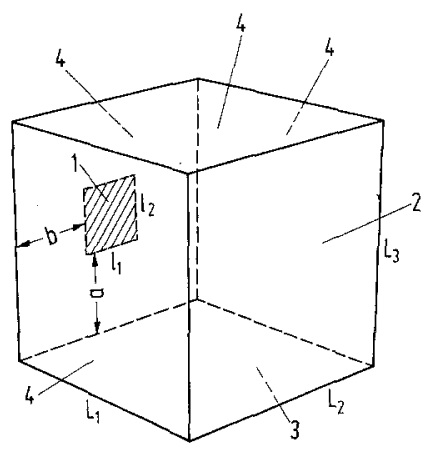

\begin{tabular}{|c|c|c|}
\hline $\mathrm{T}_{1}=0.0 \mathrm{R}$ & $\epsilon_{1}=0.99999$ & $\mathrm{~A}_{1}=1.0 \mathrm{ft}^{2}$ \\
\hline $\mathrm{T}_{2}=2460.0 \mathrm{R}$ & $\varepsilon_{2}=0.90000$ & $\mathrm{~A}_{2}=16.0 \mathrm{ft}^{2}$ \\
\hline $\mathrm{T}_{3}=1860.0 \mathrm{R}$ & $\epsilon_{3}=0.99999$ & $\mathrm{~A}_{3}=16.0 \mathrm{ft}^{2}$ \\
\hline $\mathrm{T}_{4}=2189.22 \mathrm{R}$ & $\epsilon_{4}=0.00000$ & $\mathrm{~A}_{4}=63.0 \mathrm{ft}^{2}$ \\
\hline $\mathrm{q}_{4}^{*}=0.0 \mathrm{Btu} / \mathrm{hr}$ & $=0.50000$ & $\mathrm{~b}=1.5 \mathrm{ft}$ \\
\hline $\mathrm{L}_{1}=4.0 \mathrm{ft}$ & $l_{1}=1.0 \mathrm{ft}$. & \\
\hline $\mathrm{L}_{2}=4.0 \mathrm{ft}$ & $\mathrm{l}_{2}=1.0 \mathrm{ft}$ & \\
\hline$L_{3}=4.0 \mathrm{ft}$. & $\mathrm{a}=1.5 \mathrm{ft}$ & \\
\hline
\end{tabular}

Fig. 2. 4-surface gray enclosure of Gebhart [3]

Input data for RADTQO [12] and DERGEBHOT

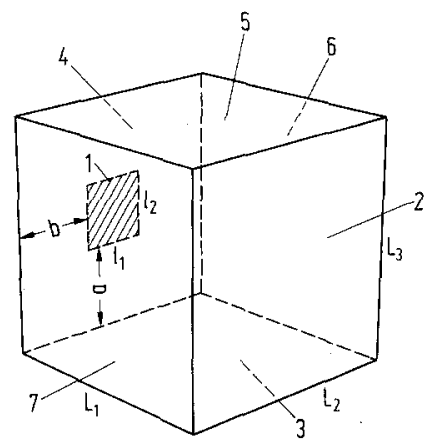

Fig. 3. 7-surface gray enclosure (modified 4-surface enclosure of Gebhart [3])

Input data for RADTQO [12] and DERGEBHOT

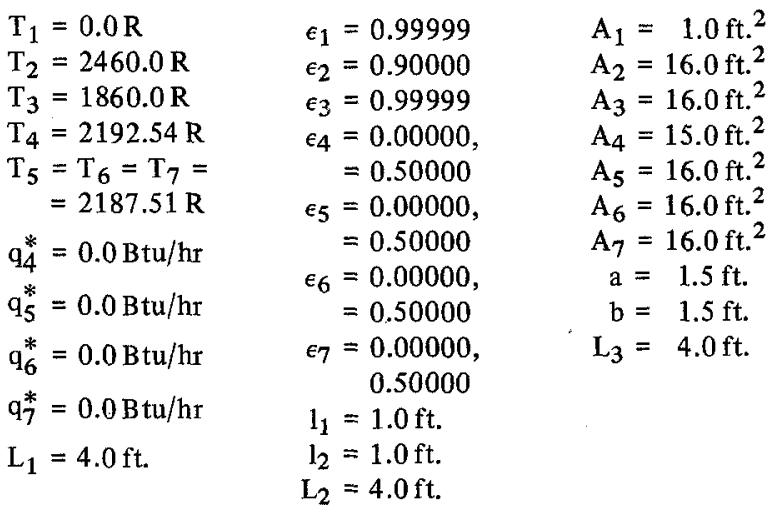

point capability of computers these values could be extended considerably closer to their theoretical values of one and zero, if desired. An emittance of 1.0 cannot be used as it would produce a reflectance of zero and an infinite value to the $\left[\mathrm{a}_{\mathbf{i j}}\right]$-matrix, Eq. (8). However, it has been established by the present authors 


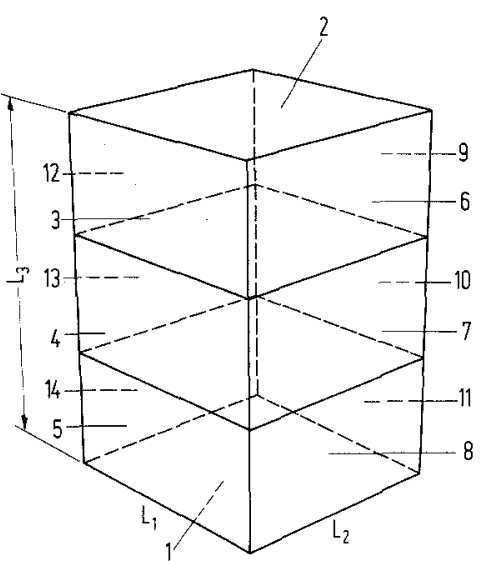

Fig. 4. 14-surface gray enclosure

Initial input data for RADTQO [12] and DERGEBHOT

$$
\begin{array}{rlrl}
\mathrm{T}_{1} & =1500.0 \mathrm{R} & \mathrm{A}_{1} & =1.0 \mathrm{ft.}^{2} \\
\mathrm{~T}_{2} & =600.0 \mathrm{R} & \mathrm{A}_{2} & =1.0 \mathrm{ft}^{2} \\
\mathrm{~T}_{3}-\mathrm{T}_{14}=800.0 \mathrm{R} & \mathrm{A}_{3}-\mathrm{A}_{14} & =0.6667 \mathrm{ft}^{2} \\
\epsilon_{1}-\epsilon_{14} & =0.65000 & \rho_{1}-\rho_{14} & =0.35000 \\
\mathrm{~L}_{1}=1.0 \mathrm{ft} . & \mathrm{L}_{2}=1.0 \mathrm{ft} . & \mathrm{L}_{3}=2.0 \mathrm{ft}
\end{array}
$$

that for this example an essentially black condition is achieved by an emittance equal to or greater than 0.99900 and, correspondingly, a reflectance equal to or less than 0.00100. Further, Gebhart considers $\mathrm{A}_{1}$ to be a non-emitter of radiation. This circumstance is established here by setting the temperature of $A_{1}$ at $0.0 \mathrm{R}$. Numerical results for this problem are summarized in Table 1. For the authors' method the computer program RADTQO [12] was used which not only computes all the radiosity fluxes and net heat transfer rates for the $n$-surfaces but determines the temperatures of all adiabatic surfaces as well. For calculations using the methods of Gebhart and Hottel and Sarofim, by Eqs. (27), (30), (38), (42), and (43), the adiabatic surface temperatures determined by RADTQO [12] were used.

As may be seen from Table 1 there is no significant difference in the results using all three methods. The tabulation in the last column represents Gebhart's independent calculations and are in essential agreement with the rest of the results. The calculations made by the present authors were completed for four different values of $\epsilon_{4}$, the emittance of the adiabatic surface, $A_{4}$. These values were $0.0,0.00001,0.50000$ and 0.99999 . To conserve space only the results for $\epsilon_{4}$ of 0.0 and 0.50000 are given in Table 1 . However, the results using the other two values for $\epsilon_{4}$ were identical to those listed in Table 1. The four different values for $\epsilon_{4}$, spanning the physically possible range for the emittance, were chosen in order to demonstrate that the computed heat transfer rates for an enclosure do not depend on the values of the emittance of the adiabatic surfaces but that the corresponding values of Gebhart's absorption factors $B_{i j}$ are significantly influenced by these emittances (see Tables 2 and 5). It is, of course, well known that the emittance of an adiabatic surface does not influence its temperature nor its radiosity heat flux. However, it is not as evident, a priori, that with a different set of absorption factors $B_{i j}$, resulting from different $\epsilon_{4}$, the computed heat transfer rates would be unaffected. The results in Table 1 demonstr: tes that this is indeed the case.

Another means for comparing the author's method

\begin{tabular}{|c|c|c|c|c|c|c|}
\hline \multirow[t]{4}{*}{ Quantity } & \multirow{4}{*}{$\begin{array}{l}\text { Authors' } \\
\text { method } \\
\text { RADTQO [12] }\end{array}$} & \multicolumn{4}{|c|}{ Eqs. $(27,30,38,39,42,43)$} & \multirow{4}{*}{$\begin{array}{l}\text { Results of } \\
\text { Gebhart [3] }\end{array}$} \\
\hline & & \multicolumn{2}{|l|}{ Gebhart } & \multicolumn{2}{|c|}{ Hottel and Sarofim } & \\
\hline & & \multicolumn{2}{|l|}{$\epsilon_{4}$} & \multicolumn{2}{|l|}{$\epsilon_{4}$} & \\
\hline & & 0.0 & 0.50000 & 0.0 & 0.50000 & \\
\hline $\mathrm{q}_{1}^{*} \mathrm{Btu} / \mathrm{hr}$ & $-40,475.2$ & $-40,475.2$ & $-40,475.2$ & $-40,475.2$ & $-40,475.2$ & $-40,500.0$ \\
\hline $\mathrm{q}_{2}^{*} \mathrm{Btu} / \mathrm{hr}$ & $399,193.2$ & $399,193.2$ & $399,193.2$ & $399,193.2$ & $399,193.2$ & $399,000.0$ \\
\hline $\mathrm{q}_{3}^{*} \mathrm{Btu} / \mathrm{hr}$ & $-360,138.2$ & $-360,138.2$ & $-360,138.2$ & $-360,000.2$ & $-360,138.2$ & $-358,500.0$ \\
\hline $\mathrm{q}_{4}^{*} \mathrm{Btu} / \mathrm{hr}$ & 0.0 & $-\quad 0.0^{*}$ & -0.00054 & 0.0 & -0.00054 & 0.0 \\
\hline$\Sigma \mathrm{q}_{\mathbf{j}}^{*} \mathrm{Btu} / \mathrm{hr}$ & $-\quad 1420.1$ & $-\quad 1420.1$ & -1420.1 & $-\quad 1420.1$ & -1420.1 & 0 \\
\hline$\% \Sigma q_{j}^{*}$ of $q_{2}^{*}$ & $-0.356 \%$ & $-0.356 \%$ & $-0.356 \%$ & $-0.356 \%$ & $-0.356 \%$ & 0 \\
\hline
\end{tabular}
[12] with that of Gebhart [3] is to compare the elements of the $B_{i j}$ matrix computed by Eq. (27) and those given by Gebhart [3] for the 4-surface enclosure, Fig. 2. The elements $\mathbf{B}_{\mathbf{i j}}$ for this enclosure determined in this way are given in Table 2 for values of $\epsilon_{4}$ of 0.0 and 0.50000 . The values in parenthesis in the upper

Table 1. Comparative results for the 4-surface enclosure

a. Input data for RADTQO [12] and DERGEBHOT listed on Fig. 2

b. $\mathrm{T}_{4}$ computed by RADTQO [12] is $2189.22 \mathrm{R}$

* -0.0 signifies a small negative number less than $10^{-6}$. 
Table 2. Absorption factor $B_{\mathrm{ij}}$ matrix for the 4-surface enclosure $\left(\epsilon_{4}=0.0\right)$

\begin{tabular}{llllll}
\hline $\mathrm{i} / \mathrm{j}$ & $\mathbf{j} 1$ & 2 & 3 & 4 & $\begin{array}{c}\sum_{j=1}^{4} B_{i j} \\
(\mathrm{i}=1,2,3,4)\end{array}$ \\
\hline 1 & 0.0143637 & 0.468677 & 0.499916 & 0.0 & 0.98296 \\
2 & $0.0332888(0.0333)$ & $0.359747(0.360)$ & 0.608723 & 0.0 & 1.00176 \\
3 & $0.0316420(0.0308)$ & $0.546941(0.557)$ & 0.420899 & 0.0 & 0.99948 \\
4 & 0.0240176 & 0.456820 & 0.519015 & 0.0 & 0.99985 \\
\hline
\end{tabular}

Absorption factor $B_{i j}$ matrix for the 4-surface enclosure $\left(\epsilon_{4}=0.50000\right)$

\begin{tabular}{llllll}
\hline $\mathrm{i} / \mathrm{j}$ & $\mathrm{j} 1$ & 2 & 3 & 4 & $\begin{array}{l}\sum_{\mathrm{j}=1}^{4} \mathrm{~B}_{\mathrm{ij}} \\
\end{array}$ \\
& & & & & \\
\hline 1 & 0.00428550 & 0.2769870 & 0.2821290 & 0.4196160 & 0.98302 \\
2 & 0.01971370 & 0.1015460 & 0.3153680 & 0.5652150 & 1.00184 \\
3 & 0.01779540 & 0.2835760 & 0.1216770 & 0.5765180 & $\mathbf{0 . 9 9 9 5 7}$ \\
4 & 0.01355880 & 0.2578920 & 0.2930030 & 0.4354630 & 0.99992 \\
\hline
\end{tabular}

Table 3. $\mathscr{F}_{\mathrm{ij}}$-matrix for the 4-surface enclosure $\left(\epsilon_{4}=0.0\right)$

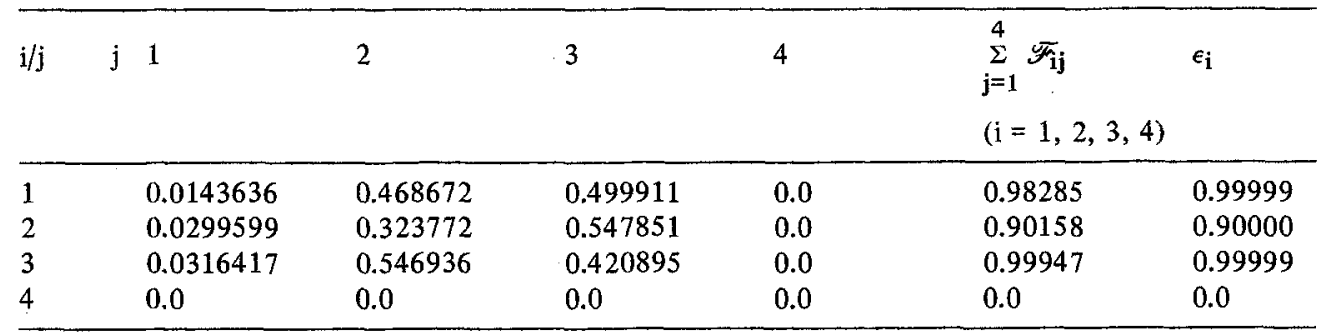

$\mathscr{F}_{\text {ij }}$-matrix for the 4-surface enclosure $\left(\epsilon_{4}=0.50000\right)$

\begin{tabular}{|c|c|c|c|c|c|c|}
\hline$i / j$ & j 1 & 2 & 3 & 4 & $\begin{array}{l}\sum_{\mathrm{j}=1}^{4} \mathscr{F}_{\mathrm{ij}} \\
(\mathrm{i}=1,2,3,4)\end{array}$ & $\epsilon_{\mathbf{i}}$ \\
\hline 1 & 0.00428551 & 0.276985 & 0.282126 & 0.419612 & 0.98301 & 0.99999 \\
\hline 2 & 0.0177423 & 0.0913910 & 0.283831 & 0.508693 & 0.90166 & 0.90000 \\
\hline 3 & 0.0177953 & 0.283573 & 0.121676 & 0.576512 & 0.99956 & 0.99999 \\
\hline 4 & 0.00677942 & 0.128946 & 0.146501 & 0.217732 & 0.49996 & 0.50000 \\
\hline
\end{tabular}

table are those reported by Gebhart [3], also for the case of $\epsilon_{4}=0.0$.

The absorption factors $B_{21}, B_{22}, B_{31}$ and $B_{32}$ in Table 2 (for $\epsilon_{4}=0.0$ ) are in essential agreement with those computed by Gebhart. Although Gebhart's method applied to this problem does not require all the $B_{i j}$, the complete $n \times n B_{i j}$-matrix with $n^{2}$ elements is always determined using Eq. (27) and the computer program DERGEBHOT. By nature of its definition the sum of the $B_{i j}$ elements in each row in Table 2 shown in the last column should be exactly unity. The fact that these elements do not sum to unity (exactly) is probably caused by some uncertainty in the third or fourth decimal place in the magnitude of the geometric view factors, $\mathrm{F}_{\mathrm{ij}}$, for the enclosure. Another contributing factor is the numerical round-off effect resulting from the large number of arithmetic operations required to compute each $\mathbf{B}_{\mathbf{i j}}$.

Although surface $A_{1}$ is at zero temperature and thus cannot emit energy to any of the other surfaces for absorption there, all the absorption factors associated with such an emission-reflection process, i. e., $B_{11}$, $B_{12}, B_{13}$ and $B_{14}$, are finite except for $B_{14}$ when $\epsilon_{4}$ is zero. This is a consequence of the fact that the absorption factors are determined only by the geometric and physical properties of the enclosure and are independent of the surface temperatures, as discussed earlier and demonstrated in Table 2. However, the 
Table 4. Comparative results for the 7-surface enclosure

a. Input data for RADTQO [12] and DERGEBHOT listed on Fig. 3

b. Adiabatic surface temperatures computed by RADTQO [12] are: $T_{4}=2192.54 \mathrm{R}$; $\mathrm{T}_{5}=\mathrm{T}_{6}=\mathrm{T}_{7}=2187.51 \mathrm{R}$

\begin{tabular}{|c|c|c|c|c|c|}
\hline \multirow{4}{*}{ Quantity } & \multirow{4}{*}{$\begin{array}{l}\text { Author's } \\
\text { method } \\
\text { RADTQO [12] }\end{array}$} & \multicolumn{4}{|c|}{ Eqs. $(27,30,38,39,42,43)$} \\
\hline & & \multicolumn{2}{|l|}{ Gebhart } & \multicolumn{2}{|c|}{ Hottel und Sarofim } \\
\hline & & \multicolumn{2}{|c|}{$\epsilon_{4}=\epsilon_{5}=\epsilon_{6}=\epsilon_{7}$} & \multicolumn{2}{|c|}{$\epsilon_{4}=\epsilon_{5}=\epsilon_{6}=\epsilon_{7}$} \\
\hline & & 0.0 & 0.50000 & 0.0 & 0.50000 \\
\hline $\mathrm{q}_{1}^{*} \mathrm{Btu} / \mathrm{hr}$ & $-40,412.98$ & $-40,412.98$ & $-40,412.98$ & $-40,412.98$ & $-40,412.98$ \\
\hline $\mathrm{q}_{2}^{*} \mathrm{Btu} / \mathrm{hr}$ & $399,613.3$ & $399,613.3$ & $399,613.3$ & $399,613.3$ & $399,613.3$ \\
\hline $\mathrm{q}_{3}^{*} \mathrm{Btu} / \mathrm{hr}$ & $-359,669.8$ & $-359,669.8$ & -359.669 .8 & $-359,669.8$ & $-359,669.8$ \\
\hline $\mathrm{q}_{4}^{*} \mathrm{Btu} / \mathrm{hr}$ & 0.0 & $-0.0^{*}$ & -0.00014 & -0.0 & -0.00014 \\
\hline $\mathrm{q}_{5}^{*} \mathrm{Btu} / \mathrm{hr}$ & 0.0 & -0.0 & -0.00005 & -0.0 & -0.00005 \\
\hline $\mathrm{q}_{6}^{*} \mathrm{Btu} / \mathrm{hr}$ & 0.0 & -0.0 & -0.00005 & -0.0 & -0.00005 \\
\hline $\mathrm{q}_{7}^{*} \mathrm{Btu} / \mathrm{hr}$ & 0.0 & -0.0 & -0.00005 & -0.0 & -0.00005 \\
\hline$\Sigma q_{j}^{*} B t u / h r$ & -469.45 & -469.45 & -469.45 & -469.45 & -469.45 \\
\hline$\% \Sigma q_{j}^{*}$ of $q_{2}^{*}$ & $-0.117 \%$ & $-0.117 \%$ & $-0.117 \%$ & $-0.117 \%$ & $-0.117 \%$ \\
\hline
\end{tabular}

* -0.0 signifies a small negative number less than $10^{-6}$.

corresponding rates of energy absorption at $A_{1}, A_{2}$, $A_{3}$ and $A_{4}$, namely $q_{11}, q_{12}, q_{13}$ and $q_{14}$, originating as emission at $A_{1}$, are each exactly zero because $T_{1}$ is zero.

Because $\mathrm{A}_{4}$ is adiabatic the emittance $\epsilon_{4}$ can be assigned any value between 0.0 and 1.0 without affecting the results. As a matter of convenience in calculation, however, it is recommended that the emittance of all adiabatic surfaces be set to 0.0 when using Gebhart's method or when determining the various $B_{i j}$ from Eq. (27). This will produce exactly 0.0 values to all absorption factors related to absorption at the adiabatic surface. These are the factors $B_{\mathbf{i} 4}$ in Table 2 .

The Hottel and Sarofim factors $\mathscr{F}_{\mathrm{ij}}$ also have been computed for the 4-surface example in Fig. 2 using Eqs. (39) and (27) and the computer program DERGEBHOT. Results of this calculation are listed in Table 3.

As may be noted from a comparision of these results with those in Table 2 , each element in the $\mathscr{F}_{\mathrm{ij}}$ matrix is related to its companion element in the $\mathrm{B}_{\mathbf{i j}}{ }^{-}$ matrix by Eq. (40). Further, the sum of each row in Table 3 , shown in the fifth column, is essentially equal to that of the emittance of the $i^{\text {th }}$ surface listed in the last column, as required by Eq. (51). The small numerical differences in these two sets of values is probably due to some decimal point uncertainties in the geometric view factors, $F_{i j}$, and numerical round-off resulting from the enormous arithmetic operation required in the computation of the matrices in Eq. (27).

A matrix for the elements $\overline{S_{i} S_{j}}$ could also be computed using Eq. (38). However, since each $\overline{S_{i} S_{j}}$ element is a simple geometric extension of $\overline{F_{1 j}}$ on the basis of $A_{1}$, Eq. (37), as separate calculation using the matrix reduction in Eq. (38) can be avoided. The corresponding $\overline{\mathrm{S}_{\mathbf{i}} \mathrm{S}_{\mathbf{j}}}$ matrix can easily be constructed by multiplying each element in the $\mathscr{F}_{\mathrm{ij}}$-matrix, Table 3 , by its corresponding surface area, $A_{i}$.

The second numerical example is shown in Fig. 3. This enclosure is identical to that in Fig. 2 but it poses a new calculation problem in that the adiabatic surface is divided into 4 separate surfaces, $A_{4}, A_{5}, A_{6}$ and $A_{7}$, making this a 7-surface enclosure. A summary of the results for this problem is given in Table 4 , for values of the emittance of the adiabatic surfaces or 0.0 and 0.50000 . As in the case of the first example, the temperatures of the adiabatic surfaces were determined by RADTQO [12] and used to complete the calculations for the results identified as "Gebhart" and "Hottel and Sarofim" using the authors" program DERGEBHOT. For this example there are no independent calculations available for comparision.

As shown by Table 4 there is an exact correspondence between the results of the three methods. Also, the influence of the emittance of the adiabatic surfaces $A_{4}, A_{5}, A_{6}$ and $A_{7}$ is negligible on the calculation of 
Table 5. Absorption factor $B_{i j}$ matrix for the 7-surface enclosure $\left(\epsilon_{4}=\epsilon_{5}=\epsilon_{6}=\epsilon_{7}=0.0\right)$

\begin{tabular}{|c|c|c|c|c|c|c|c|c|}
\hline$i / j$ & 1 & 2 & 3 & 4 & 5 & 6 & 7 & $\begin{array}{l}\sum_{j=1}^{7} B_{i j} \\
i=1, \ldots, 7)\end{array}$ \\
\hline 1 & 0.0159081 & 0.472315 & 0.503810 & 0.0 & 0.0 & 0.0 & 0.0 & 0.99203 \\
\hline 2 & 0.0323387 & 0.359179 & 0.608085 & 0.0 & 0.0 & 0.0 & 0.0 & 1.00050 \\
\hline 3 & 0.0315906 & 0.547225 & 0.421230 & 0.0 & 0.0 & 0.0 & 0.0 & 1.00005 \\
\hline 4 & 0.0164970 & 0.460030 & 0.524039 & 0.0 & 0.0 & 0.0 & 0.0 & 1.00057 \\
\hline 5 & 0.0263256 & 0.456021 & 0.517691 & 0.0 & 0.0 & 0.0 & 0.0 & 1.00004 \\
\hline 6 & 0.0263256 & 0.456021 & 0.517691 & 0.0 & 0.0 & 0.0 & 0.0 & 1.00004 \\
\hline 7 & 0.0263256 & 0.456021 & 0.517691 & 0.0 & 0.0 & 0.0 & 0.0 & 1.00004 \\
\hline
\end{tabular}

Absorption factor $B_{i j}$ matrix for the 7-surface enclosure $\left(\epsilon_{4}=\epsilon_{5}=\epsilon_{6}=\epsilon_{7}=0.50000\right)$

\begin{tabular}{|c|c|c|c|c|c|c|c|c|}
\hline$i / j$ & 1 & 2 & 3 & 4 & 5 & 6 & 7 & $\begin{array}{l}\sum_{j=1}^{7} B_{i j} \\
(i=1, \ldots, 7)\end{array}$ \\
\hline 1 & 0.00509208 & 0.278130 & 0.283295 & 0.0391638 & 0.128772 & 0.128772 & 0.128772 & 0.99200 \\
\hline 2 & 0.0197074 & 0.101360 & 0.315158 & 0.134419 & 0.143255 & 0.143255 & 0.143255 & 1.00041 \\
\hline 3 & 0.0177627 & 0.283629 & 0.121739 & 0.138082 & 0.146246 & 0.146246 & 0.146246 & 0.99995 \\
\hline 4 & 0.00524832 & 0.258131 & 0.294765 & 0.040265 & 0.133986 & 0.133986 & 0.133986 & 1.00053 \\
\hline 5 & 0.0161479 & 0.257845 & 0.292489 & 0.125530 & 0.420419 & 0.132951 & 0.132951 & 0.99996 \\
\hline 6 & 0.0161479 & 0.257845 & 0.292489 & 0.125530 & 0.132951 & 0.0420419 & 0.132951 & 0.99996 \\
\hline 7 & 0.0161479 & 0.257845 & 0.292489 & 0.125530 & 0.132951 & 0.132951 & 0.0420419 & 0.99996 \\
\hline
\end{tabular}

Table 6. $\mathscr{F}_{\mathrm{ij}}$-matrix for the 7-surface enclosure $\left(\epsilon_{4}=\epsilon_{5}=\epsilon_{6}=\epsilon_{7}=0.0\right)$

\begin{tabular}{|c|c|c|c|c|c|c|c|c|c|}
\hline$i / j$ & j 1 & 2 & 3 & 4 & 5 & 6 & 7 & $\begin{array}{l}\sum_{\mathrm{j}=1}^{7} \mathscr{F}_{\mathrm{ij}} \\
(\mathrm{i}=1, \ldots,\end{array}$ & $\epsilon_{\mathrm{i}}$ \\
\hline 1 & 0.0159080 & 0.472310 & 0.503805 & 0.0 & 0.0 & 0.0 & 0.0 & 0.99202 & 0.99999 \\
\hline 2 & 0.0299148 & 0.323262 & 0.547276 & 0.0 & 0.0 & 0.0 & 0.0 & 0.90045 & 0.90000 \\
\hline 3 & 0.0315903 & 0.547219 & 0.421226 & 0.0 & 0.0 & 0.0 & 0.0 & 1.00004 & 0.99999 \\
\hline 4 & 0.0 & 0.0 & 0.0 & 0.0 & 0.0 & 0.0 & 0.0 & 0.0 & 0.0 \\
\hline 5 & 0.0 & 0.0 & 0.0 & 0.0 & 0.0 & 0.0 & 0.0 & 0.0 & 0.0 \\
\hline 6 & 0.0 & 0.0 & 0.0 & 0.0 & 0.0 & 0.0 & 0.0 & 0.0 & 0.0 \\
\hline 7 & 0.0 & 0.0 & 0.0 & 0.0 & 0.0 & 0.0 & 0.0 & 0.0 & 0.0 \\
\hline
\end{tabular}

$\mathscr{F}_{\mathrm{ij}}$-matrix for the 7-surface enclosure $\left(\epsilon_{4}=\epsilon_{5}=\epsilon_{6}=\epsilon_{7}=0.50000\right)$

\begin{tabular}{|c|c|c|c|c|c|c|c|c|c|}
\hline $\mathrm{i} / \mathrm{j}$ & j 1 & 2 & 3 & 4 & 5 & 6 & 7 & $\begin{array}{l}\sum_{\mathrm{j}=1}^{7} \mathscr{F}_{\mathrm{ij}} \\
(\mathrm{i}=1, \ldots, 7)\end{array}$ & $\epsilon_{\mathrm{i}}$ \\
\hline 1 & 0.00509203 & 0.278128 & 0.283292 & 0.0391634 & 0.128771 & 0.128771 & 0.128771 & 0.99199 & 0.99999 \\
\hline 2 & 0.0177366 & 0.0912243 & 0.283642 & 0.120977 & 0.128930 & 0.128930 & 0.128930 & 0.90037 & 0.90000 \\
\hline 3 & 0.0177625 & 0.283626 & 0.121738 & 0.138081 & 0.146244 & 0.146244 & 0.146244 & 0.99994 & 0.99999 \\
\hline 4 & 0.00262416 & 0.129066 & 0.147382 & 0.0202132 & 0.0669928 & 0.0669928 & 0.0669928 & 0.50026 & 0.50000 \\
\hline 5 & 0.00807395 & 0.128923 & 0.146244 & 0.0627648 & 0.0210209 & 0.0669928 & 0.0664755 & 0.49998 & 0.50000 \\
\hline 6 & 0.00807395 & 0.128923 & 0.146244 & 0.0627648 & 0.0664755 & 0.0210209 & 0.0664755 & 0.49998 & 0.50000 \\
\hline 7 & 0.00807395 & 0.128923 & 0.146244 & 0.0627648 & 0.0664755 & 0.0664755 & 0.0210209 & 0.49998 & 0.50000 \\
\hline
\end{tabular}


Table 7. Results for the 14-surface enclosure

a. Input data for RADTQO [12] and DERGEBHOT listed on Fig. 4

\begin{tabular}{rrrrr}
\hline & \multicolumn{2}{c}{$\begin{array}{l}\text { Authors' method } \\
\text { RADTQO [12] }\end{array}$} & \multicolumn{2}{c}{ Eqs. $(27,30,38,39,42,43)$} \\
\cline { 3 - 5 } $\mathrm{j}$ & $\mathbf{J}_{\mathbf{j}}$ Btu/hr-ft. $^{2}$ & $\mathrm{q}_{\mathbf{j}}^{*}$ Btu/hr & $\mathrm{q}_{\mathbf{j}}^{*}$ Btu/hr & $\mathrm{q}_{\mathbf{j}}^{*}$ Btu/hr \\
\hline 1 & 6038.40 & 4900.48 & 4900.48 & 4900.48 \\
2 & 557.98 & -623.71 & -623.71 & -623.71 \\
3 & 765.62 & -78.70 & -78.70 & -78.70 \\
4 & 893.70 & -237.27 & -237.27 & -237.27 \\
5 & 1296.10 & -735.49 & -735.49 & -735.49 \\
6 & 765.62 & -78.70 & -78.70 & -78.70 \\
7 & 893.70 & -237.27 & -237.27 & -237.27 \\
8 & 1296.10 & -735.49 & -735.49 & -735.49 \\
9 & 765.62 & -78.70 & -78.70 & -78.70 \\
10 & 893.70 & -237.27 & -237.27 & -237.27 \\
11 & 1296.10 & -735.49 & -735.49 & -735.49 \\
12 & 765.62 & -78.70 & -78.70 & -78.70 \\
13 & 893.70 & -237.27 & -237.27 & -237.27 \\
14 & 1296.10 & -735.49 & -735.49 & -735.49 \\
\hline & $\mathrm{q}_{\mathbf{j}}^{*}$ & 70.87 & 70.87 & 70.87 \\
\hline
\end{tabular}

the various net heat transfer rates. As in the case of the 4-surface enclosure of Fig. 2 these calculations were also performed with emittances of the adiabatic surfaces of 0.00001 and 0.99999 with results identical to those given in Table 4.

The $\left[\mathrm{B}_{\mathrm{ij}}\right]$-matrix computed from Eq. (27) and the $\left[\mathscr{F}_{\mathrm{ij}}\right]$-matrix from Eq. (39) using the program DERGEBHOT are given in Tables 5 and 6 for the 7-surface enclosure of Fig. 3 with emittances of the adiabatic surface equal to 0.0 and 0.50000 . The $\left[\overline{\mathrm{S}_{\mathrm{i}} \mathrm{S}_{\mathrm{j}}}\right]$-matrix is not tabulated since each of its elements may be obtained by multiplying each of the elements in the $\mathscr{F}_{i j}$ matrix by $A_{i}$. Also listed in Tables 5 and 6 are the sums of each row of the matrixes. The row sums in the $\left[B_{\mathbf{i j}}\right]$-matrix are very close to unity as required by Eq. (50), the differences from unity being caused by numerical uncertainty in the geometric view factors as well as round-off effects in the arithmetic operations. The sum of the rows in the $\mathscr{F}_{i j}$-matrix is essentially equal to $\epsilon_{\mathrm{i}}$ as required by Eq. (51). The values of $\epsilon_{\mathrm{i}}$ are included in the last column in Table 6 for comparison with the row sums.

The last example, shown in Fig. 4 with its input data, is a 14-surface enclosure having specified surface temperatures. It is included here to extend the comparison of the three methods and to include a more comprehensive problem. The results for the 14-surface enclosure are given in Table 7.

As in the case of the other examples the results for the 14-surface enclosure using the three methods are in complete agreement.
The absorption factors $B_{i j}$ and the factors $\mathscr{F}_{i j}$ for the 14-surface enclosure in Fig. 4 were also computed using the program DERGEBHOT. However, in the interest of conserving space these data will not be included in this paper. Each set of data would involve 196 separate numerical entries.

\section{Conclusions}

The equivalence of three algebraic methods for the calculation of radiation heat exchange in an enclosure is demonstrated. The methods compared are those of Hottel and Sarofim [1, 2], Gebhart [3, 4] and one published recently by the authors [12]. Equivalence between the methods is established by deriving the absorption factors, $B_{\mathbf{i j}}$, of Gebhart and the total exchange factors, $\overrightarrow{S_{i} S_{j}}$, and the total view factors, $\mathscr{F}_{\mathrm{i} j}$, of Hottel and Sarofim using the authors' formulation [12] as a starting point. Numerical comparison is also made using three enclosures as examples and computing the radiant exchange rates by the three methods. Essentially exact correspondence is found between the numerical results using each of the three methods to compute the radiant interchange. The computer program used to compute the derived forms of the methods of Gebhart and Hottel and Sarofim is named DERGEBHOT. Numerical results using the authors' method are determined from a computer program named RADTQO [12].

The factors $\overline{S_{i} S_{j}}$ and $\mathscr{F}_{i j}$ of Hottel and Sarofim are shown to be other forms of an absorption factor. 


\section{Acknowledgements}

The authors wish to acknowledge the assistance of the College of Engineering in providing funds for the use of the University of Michigan IBM 360/67 digital computer and terminal system with which all the data reported were obtained. The second author received Department of Mechanical Engineering fellowship support.

\section{References}

1. Hottel, H. C.: Radiant-Heat Transmission. Chap. 4 in Heat Transmission by W. H. McAdams, McGraw-Hill Book Co., Third Edition, 1954.

2. Hottel, H. C., Sarofim, A. F.: Radiative Transfer, McGraw Hill Book Co., 1967.

3. Gebhart, B.: Heat Transfer, McGraw Hill Book Co., Chap. 5, 1971.

4. Gebhart, B.: Surface Temperature Calculations in Radiant Surroundings of Arbitrary Complexity for Gray, Diffuse Radiation. Intern. J. Heat Mass Transfer 3 (1961) $341 / 346$.

5. Sparrow, E. M.: On the Calculation of Radiant Interchange Between Surfaces. In Modern Developments in Heat Transfer, edited by W. Ibele, Academic Press (1963) 181/212.

6. Sparrow, E. M., Cess, R. D.: Radiative Heat Transfer, Brooks/Cole Publishing Co. 1966.

7. Oppenheim, A. K.: Radiation Analysis by the Network Method. Transactions ASME 78, No. 1, May 1956, 725/735. (Presented at the ASME Annual Meeting Nov. 28-Dec. 3, 1954.)
8. Eckert, E. R. G., Drake, R. M., Jr.: Heat and Mass Transfer, McGraw Hill Book Co., 1959.

9. Love, T. J.: Radiative Heat Transfer, Charles E. Merrill Publishing Co., 1968.

10. Wiebelt, J. A.: Engineering Radiation Heat' Transfer, Holt, Rinehart and Winston, 1966.

11. Siegel, R., Howell, J. R.: Thermal Radiation Heat Transfer, McGraw Hill Book Co., 1972.

12. Clark, J. A., Korybalski, M. E.: Radiation Heat Transfer in an Enclosure Having Surfaces Which Are Adiabatic or of Known Temperature. Proceedings, First National Heat and Mass Transfer Conference, Madras, India, Dec. 6-8, 1971.

13. Gebhart, B.: Personal Communication, J. A. Clark, July 23, 1971.

John A. Clark,

Professor of Mechanical Engineering and Chairman

Department of Mechanical Engineering

University of Michigan,

Ann Arbor 48 104, Michigan, USA

Michael E. Korybalski, Graduate Assistant, Department of Mechanical Engineering University of Michigan

Received May 29, 1973 